\title{
Correlation of odontogenic infection severity score with C-reactive protein levels on the patient with odontogenic infection in Dr Hasan Sadikin General Hospital Bandung
}

\author{
Ariyaka Niastya Prihandana ${ }^{1 *}$, Harmas Yazid Yusuf², Agus Nurwiadh², Leni \\ Lismayanti ${ }^{3}$ \\ ${ }^{1}$ Medical Staff Group of Oral and Maxillofacial Surgery, Gunung Jati Public Hospital of Cirebon, \\ Indonesia \\ ${ }^{2}$ Department of Oral and Maxillofacial Surgery, Faculty of Dentistry Universitas Padjadjaran, \\ Indonesia \\ ${ }^{3}$ Department of Clinical Pathology, Faculty of Medicine Universitas Padjadjaran, Indonesia
}

\begin{abstract}
Introduction: Head and neck infections commonly caused by spreading odontogenic infection. Odontogenic infections could cause a local and systemic manifestation, with mild to severe complications according to its severity. Assessment of the severity of odontogenic infections is essential to determine the prognosis, which is assessed through local and systemic parameters. Laboratory examination used to examine the biological marker that indicates the ongoing infection. C-Reactive Protein (CRP) is a protein synthesized by hepatocytes in response to the inflammatory process in the body including odontogenic infection. The objective of this study was to analyze the severity score of odontogenic infections with CRP levels in patients with odontogenic infections. Methods: This study used an analytic study with cross-sectional approach on 30 patients Sample size is determined by calculations according to Hosmer and Lemeshow and diagnosed with odontogenic infections that came to Dr Hasan Sadikin General Hospital Bandung. Assessment of severity score in odontogenic infections and measurement of quantitative CRP levels with Dimension tool was conducted. Correlation between odontogenic infection severity score and CRP levels was found using regression and correlation tests. Results: There was a very strong and significant correlation ( $p$-value $<0.05$ ) between the severity of odontogenic infections and CRP levels in odontogenic infection patients with a correlation coefficient $r=0.84(p=0.0000000036)$. Conclusion: There is a positive correlation between CRP levels and the severity score of odontogenic infection, CRP levels higher and the severity score of odontogenic infection high.
\end{abstract}

Keywords: CRP; odontogenic infections; severity score.

p-ISSN: 1979-0201; e-ISSN: 2549-6212; Available from: http://jurnal.unpad.ac.id/pjd/article/view/21252

DOI: 10.24198/pid.vol33no1.21252

Submission: Apr 06, 2019; Accepted: Dec 18, 2020; Published online: Mar 31, 2021

"Corresponding author: Ariyaka Niastya Prihandana, Medical Staff Group of Oral and Maxillofacial Surgery, Gunung Jati Public Hospital of Cirebon, Indonesia. 56, Jalan Kesambi, Cirebon, West Java, Indonesia, 45133. Phone: +62 811-2060-087; e-mail: silversurfer_1987@yahoo.com 


\section{INTRODUCTION}

Odontogenic infection may cause a life-threatening complications, such as upper airway obstruction, descending mediastinitis, jugular venous thrombosis, carotid artery rupture, respiratory distress, septic shock and disseminated intra vascular coagulopathy (DIC). ${ }^{1}$ It is of the utmost importance to assess the odontogenic infections as early as possible. Clinical signs may be delayed or not have enough information to provide an interpretation of the severity of an infection. One of the supporting methods to predict and measure the severity of odontogenic infection is by examining the total leukocyte count and erythrocyte sedimentation rate. ${ }^{2}$ This examination has limited predictability to accurately determine and assess the severity of infection, therefore an alternative examination that can accurately assess and predict the severity of an infection is needed. ${ }^{1,2,3}$

The stages of odontogenic infection begin with inoculation which starts with the initial spread of microbes/infectious agent into the soft tissues and characterized by soft, sticky and slightly smooth tissue swelling accompanied by a slight redness. ${ }^{4}$ During the cellulitis stage the inflammatory process reaches a peak and causes hyperemic, hard, and very painful swelling accompanied by trismus or inability to push the tongue forward. ${ }^{4,5,6}$ The next stage is abscess formation, where there is a process of necrosis with a clinical appearance of fluctuation. ${ }^{7}$ The final stage of odontogenic infection is an abscess rupture that occurs spontaneously or with therapeutic drainage. ${ }^{8}$ Stages of infection can be used as a reference to understand how severe untreated odontogenic infections can spread to the head cavity and deep neck fascia. ${ }^{7,8,9}$ Clinical manifestations of systemic inflammation known as Systemic Inflammatory Response Syndrome (SIRS). ${ }^{10}$ Other factors that play a role in determining the degree of severity are the body immune system and concomitant systemic diseases such as diabetes mellitus which have a lower body resistance to severe odontogenic infections (Table 1). ${ }^{10,11}$

Serum C-reactive protein (CRP) is one of the acute-phase, a protein synthesized by hepatocytes in response to tissue damage..$^{12} \mathrm{C}$-reactive protein has a normal level of less than $0.3 \mathrm{mg} / \mathrm{dL}$ and will increase significantly if an inflammatory process occurs due to trauma, surgery or infection. ${ }^{13}$ CRP functions in the immune system in complement activation, elimination of antigens and plays a role in the process of phagocytosis by activating neutrophils. ${ }^{14}$ CRP has a short half-life (5-7 hours), so CRP is considered a more sensitive indicator than total leukocyte count and erythrocyte sedimentation rate in assessing the severity of infection. 12,13,14

The severity score of odontogenic infection used in this research based on several parameters such as systemic inflammatory response syndrome (SIRS), trismus condition, dysphagia, involvement of fascial space, sign of dehydration and comorbid. Scoring system was created by Sainuddin et al. ${ }^{14}$ Odontogenic infections severity assessment is very important to plan a therapy and predict the prognosis of the disease course. ${ }^{15}$ In addition to physical examination, laboratory findings are needed to help determine the severity in patients with odontogenic infections. This study was aimed to analyse the correlation between the severity of odontogenic infections with $\mathrm{C}$-reactive protein (CRP) levels as a laboratory finding in patients with odontogenic infections.

\section{METHODS}

This study used an analytic study with a crosssectional approach on patients diagnosed with odontogenic infections that came to $\mathrm{Dr}$ Hasan Sadikin General Hospital Bandung from May to December 2018. The subjects of the study were 30 patients with odontogenic infections, sample size is determined by the formula for hypothesis testing using coefficient $r$ with calculations according to Hosmer and Lemeshow with a 95\% confidence level and a $95 \%$ power test. The inclusion criteria was (1) age between 18-55 years old, (2) from history taking there is no immunocompromised state, abnormalities in liver function, osteoarthritis, neoplastic diseases and cardiovascular disease. The exclusion criteria was (1) damage to blood sample occurs, (2) the patient deceased before all the examination completed, (3) the patient needed to resuscitate prior to admission.

CRP levels are measured from blood samples drawn from the patients and used 
the RCRP method with the dimension clinical chemistry system to calculate quantitative CRP. The normal reference value in adult individuals is $0.2-0.33 \mathrm{mg} / \mathrm{dl}$. Assessment of severity score in odontogenic infections with physical examination and measurement of quantitative CRP levels.
Conclusion was made to compare the results of CRP levels and the score of the severity in patients with odontogenic infections. Correlation between odontogenic infection severity score and CRP levels was found using regression and Pearson correlation test.

Table 1. The severity of odontogenic infection ${ }^{14}$

\begin{tabular}{|c|c|c|c|c|}
\hline \multicolumn{2}{|c|}{ Criteria } & \multirow{2}{*}{$\frac{\text { Score }}{1}$} & \multirow[t]{2}{*}{ Max. score } & \multirow[t]{2}{*}{ Pt. score } \\
\hline \multirow{4}{*}{ Systemic inflammatory response syndrome } & Temperature $>38.3^{\circ} \mathrm{C}$ or $<35,3^{\circ} \mathrm{C}$ & & & \\
\hline & Heart rate $>90 \mathrm{bpm}$ & 1 & \multirow{3}{*}{4} & \\
\hline & $\mathrm{RR}>20 \mathrm{x} / \mathrm{min}$ & 1 & & \\
\hline & WBC $<4$ or $>12 \times 109$ & 1 & & \\
\hline \multirow{2}{*}{ Trismus } & Moderate $<2 \mathrm{~cm}$ & 3 & \multirow{2}{*}{4} & \\
\hline & Severe $<1 \mathrm{~cm}$ & 4 & & \\
\hline \multirow{3}{*}{ Dysphagia } & Mild - able to swallow most foods & 2 & \multirow{3}{*}{5} & \\
\hline & Moderate - unable to swallow fluids & 4 & & \\
\hline & Severe - drooling saliva & 5 & & \\
\hline \multirow{3}{*}{ Collection in facial space } & Low severity space & 1 & \multirow{4}{*}{5} & \\
\hline & Moderate severity space & 2 & & \\
\hline & High severity space & 4 & & \\
\hline \multicolumn{2}{|c|}{ Collection in 2 or more fascial space } & 5 & & \\
\hline \multicolumn{2}{|c|}{ Sign of dehydration (|BP/†Ureum/」Skin turgor) } & 1 & \multirow{2}{*}{2} & \\
\hline \multicolumn{2}{|c|}{ Comorbid: DM/Immuno-compromised states } & 1 & & \\
\hline
\end{tabular}

Note: 0 = Normal; $1-8$ = Mild severity score; 9-16 = Moderate severity score; $>16$ = Severe severity score; Low severity space: Vestibular, subperiosteal, infraorbital, buccal; Moderate severity space: Submandibula, submental, sublingual, pterygomandibular, submasseter, superficial temporal, infratemporal; High severity space : Lateral pharyngeal, retropharyngeal, pretracheal, danger space, mediastinum, intracranial

\section{RESULTS}

In this study it was seen that out of 30 patients suffering from odontogenic infections and fulfilling inclusion criteria, there were no significant differences based on 14 male and 16 female gender. While the distribution of research subjects based on age shows that the age range between 43-55 years is the highest amount (53.3\%) with CRP mean value was $15.5 \mathrm{mg} / \mathrm{dL}$ (Table 2).

Table 2. Characteristic of study subjects

\begin{tabular}{lccc}
\hline \multicolumn{1}{c}{ Variable } & $\mathrm{n}$ & $\%$ & Mean value \\
\hline Sex & & & \\
Male & 14 & 46.7 & \\
Female & 16 & 53.3 & \\
\hline Age & & & \\
18 - 30 years old & 8 & 26.7 & \\
31 - 42 years old & 6 & 20.0 & \\
43 - 55 years old & 16 & 53.3 & $10.2(4.1)$ \\
\hline Severity score of odontogenic infection & & & \\
Mild (score 1-8) & 10 & 33.3 & \\
Moderate (score 9-16) & 19 & 63.3 & $\mathbf{1 5 . 5 ( 8 . 3 )}$ \\
Severe (score 17-20) & 1 & 3.3 & \\
\hline CRP level & & & \\
\hline
\end{tabular}


Characteristics data from research subjects based on SIRS scores, trismus, dysphagia, involved spaces and signs of dehydration or comorbidities from severity of infections seen in Table 3 .

Table 3. Characteristic of severity score in odontogenic infection

\begin{tabular}{|c|c|c|}
\hline Variable & $\mathrm{n}$ & $\%$ \\
\hline \multicolumn{3}{|l|}{ SIRS score } \\
\hline 0 & 1 & 3.3 \\
\hline 1 & 12 & 40.0 \\
\hline 2 & 10 & 33.3 \\
\hline 3 & 7 & 23.3 \\
\hline 4 & 0 & 0.0 \\
\hline \multicolumn{3}{|l|}{ Trismus score } \\
\hline Normal (0) & 12 & 40.0 \\
\hline Moderate (3) & 15 & 50.0 \\
\hline Severe (4) & 3 & 10.0 \\
\hline \multicolumn{3}{|l|}{ Dysphagia score } \\
\hline Normal (0) & 1 & 3.3 \\
\hline Mild (2) & 22 & 73.3 \\
\hline Moderate (4) & 7 & 13.3 \\
\hline Severe (5) & 0 & 0.00 \\
\hline \multicolumn{3}{|l|}{ Facial space score } \\
\hline Low space risk (1) & 2 & 6.7 \\
\hline Moderate space risk (2) & 9 & 30.0 \\
\hline Severe space risk (4) & 0 & 0.0 \\
\hline More than 1 space involved (5) & 19 & 63.3 \\
\hline \multicolumn{3}{|l|}{ Dehydration/Comorbid } \\
\hline No dehydration and comorbid & 20 & 66.7 \\
\hline Dehydration or comorbid & 7 & 23.3 \\
\hline Dehydration and comorbid & 3 & 10.0 \\
\hline
\end{tabular}

The mean values of the severity scores of odontogenic infections and CRP levels are shown in table 4.

Table 4. Mean value of severity score and CRP Level

\begin{tabular}{lcccc}
\hline $\begin{array}{c}\text { Severity } \\
\text { score }\end{array}$ & $\mathrm{n}$ & $\%$ & Mean score & $\begin{array}{c}\text { Mean value of } \\
\text { CRP level } \\
\text { (mg/dL) }\end{array}$ \\
\hline Mild & 10 & 33.3 & 5.8 & 7.80 \\
Moderate & 19 & 63.3 & 12 & 18.72 \\
Severe & 1 & 3.3 & 20 & 32.44 \\
\hline
\end{tabular}

The results of the regression analysis of the correlation between the severity of odontogenic infections with CRP levels showed a very strong correlation of $r=0.84$ or by $70 \%$ with $p$ value $<0.05$. Therefore there was a statistically significant correlation between the severity of odontogenic infections with CRP levels. Based on correlation regression analysis it was found that there was a correlation between the severity of odontogenic infections and CRP levels. To rule out the correlation between the severity of odontogenic infections and CRP levels the Pearson correlation test was done. The results shown in Table 5.

Table 5. Correlation between severity score of odontogenic infection with CRP levels

\begin{tabular}{lcc}
\hline \multicolumn{1}{c}{ Variable } & $\begin{array}{c}\text { Coefficient } \\
\text { correlation }\end{array}$ & p-value \\
\hline $\begin{array}{l}\text { Severity score of odontogenic } \\
\text { infection in general - CRP level }\end{array}$ & 0.839 & 0.001 \\
\hline
\end{tabular}

Notes: Data analysis using Pearson correlation test, $\mathrm{p}<0.05$ considered as significant

Based on the results of Pearson's analysis, the test uses $t$ statistics which give a value of $t_{\text {count }}=8.143$ with $p$-value of 0.001 which is statistically significant. With a value of $r=0.84$, the correlation is very strong which is statistically significant.

\section{DISCUSSION}

This study shows from examination based on SIRS parameters, patients with 1 symptom of SIRS was $40,0 \%$ and 2 signs of SIRS was $33,3 \%$ of all the study subjects. SIRS parameters appear due to inflammation caused by odontogenic infection. SIRS is useful to determine whether a patient has a septic condition or not, an odontogenic infection patient with septic conditions has a worse prognosis when compared with patients of odontogenic infections without septic conditions. This result is similar to the previous research which suggested that odontogenic patients with septic conditions had a longer hospital stay. ${ }^{21}$

The condition of trismus in the subject of this study was due to $80 \%$ of the subjects suffering from infection in the submandibular space, the spread of infection in the submandibular space will cause trismus if the medial pterygoid muscle was infected. ${ }^{21,22,23}$ In odontogenic infections that spread to the sublingual and submandibular space the swelling could develop on the mucosa at the floor of the mouth, which causes the tongue to push upwards to the palate and lateral and cause dysphagia. ${ }^{24}$ Apart from sublingual inflammation, infection of the pterygomandibular, 
retropharyngeal and parapharyngeal can also cause dysphagia. ${ }^{24,25}$ Other serious complications that can be caused by odontogenic infections in the head and neck area is respiratory tract obstruction caused by swelling in the floor of the mouth, and abscess formation which will narrow the airways. ${ }^{26}$ The condition of trismus and dysphagia is a clinical parameter that can detect signs of respiratory tract obstruction. ${ }^{26,27}$

From the results of clinical examination to see involvement of facial space, it was found $63.33 \%$ of patients who had involvement of more than one facial space, and $80 \%$ of them suffered infections in the submandibular space, which consistent with research conducted by Opitz et al. ${ }^{25}$ and Heim et al. ${ }^{20}$ explaining that mandibular molar teeth are the most common focus of infection in odontogenic infections because their root tips reach the mylohyoid muscle so that without proper management of the periapical infections can spread to the submandibular space or parapharyngeal space. ${ }^{28,29}$ The involvement of more than one space can occur due to the delay of the patient in seeking appropriate treatment for odontogenic infections. ${ }^{9,11,28}$

In this study, $66.67 \%$ of patients did not have comorbid or signs of dehydration. This is not in accordance with the research conducted by Bagul et al. $^{26}$ in 2016 which stated that odontogenic infections generally have comorbid predisposing factors, for example: diabetes mellitus, obesity, immunosuppression or arterial hypertension which have systemic consequences. ${ }^{25}$ In addition to comorbid factors, Bagul et al. ${ }^{26}$ also explained that the severity of odontogenic infections could be due to other factors such as advanced adulthood, tobacco smoking habits, drug abuse, poverty and patients with poor social conditions which can also cause a decline in the immune system.

In this study a significant increase in CRP levels was found in patients with odontogenic infections, so it can be concluded that the odontogenic infection caused an inflammation which triggered systemic response in the body manifested by an increase in CRP level. In conditions of infection, IL- 6 serum, a- 1 antitrypsin concentrations increase with the severity of infection so that CRP level also increases. ${ }^{26,27}$ Parameters of the severity score of odontogenic infection such as SIRS, trismus, dysphagia and collection of fascial space are measured to determine the inflammation condition due to odontogenic infection. Dehydration and comorbid are factors that can contribute to the response of the body to inflammation and infection condition. ${ }^{29,30}$

The correlation between the severity score of odontogenic infections and CRP levels from subjects analyse with Pearson Correlation test and the result is $p$ value $<0.05$ with $r$ coefficient $=0.84$. Therefore there is a statistically significant positive correlation between CRP level and odontogenic severity score. CRP levels on odontogenic infection increase with positive correlation with its severity score. It means that the higher the severity score of the odontogenic infection, the CRP levels increase simultaneously.

Determining severity of odontogenic infection is essential to plan therapy, monitoring of clinical state of the patient and to predict prognosis. Combination of physical examination and supporting examination such as biomarker used to determine the severity of odontogenic infection. From this study it can be concluded that CRP level can be used as a biomarker to support determining the severity of odontogenic infection in clinical practice.

Severity score of odontogenic infection based on parameter to measure how the inflammation state (SIRS, trismus, dysphagia and fascial space collection) of the subject and factors (dehydration and comorbid) that directly influence the subject systemic response to inflammation and odontogenic infections state. The higher the score of the severity directly proportional with the CRP level.

This study has limitations in the form of the distribution of patients who are subject to uneven research. There is only one patient with a severity score of odontogenic infection.

\section{CONCLUSION}

This study shows a positive correlation between the severity of odontogenic infections and the levels of C-reactive protein (CRP).

\section{REFERENCES}

1. Berkovics C. Local Anesthesis for the Dental Hygienist, handbook of BSC level Dental 
Hygiene Program. Chapter 2. University of Szeged. 2011. p. 57-62.

2. Hupp JR, Ellis El, Tucker MR. Contemporary Oral and Maxillofacial Surgery. $6^{\text {th }}$ ed. St. Louis: Mosby-Elsevier. 2014. p. 296-338.

3. Han X, An J, Zhang Y, Gong X, He Y. Risk factors for life-threatening complications of maxillofacial space infection. J Craniofac Surg. 2016 Mar;27(2):385-90. DOI: 10.1097/ SCS.0000000000002416

4. Salgado FJ, Arias P. Acute Phase Proteins as Early Non-Specific Biomarkes of Human and Veterinary Diseases, Chapter 7: Acute Phase Proteins as Biomarkers of Disease: From Bench to Clinical Practice. 2011. p. 127-65.

5. Bali RK, Sharma P, Gaba S, Kaur A, Ghanghas P. A review of complications of odontogenic infections. Natl J Maxxilofac Surg. 2015 Jul-Dec;6(2):136-43. DOI: 10.4103/09755950.183867

6. Gronholm L. Severe Odontogenic Infections. Studies on Local and Systemic Odontogenic Infections Requiring Hospital Care. Academic Dissertation, Medical Faculty of The University Helsinki. 2012. p. 35-40.

7. Ogle OE. Odontogenic infections. Dent Clin North Am. 2017;61(2):236-52. DOI: 10.1016/j. cden.2016.11.004

8. Vytla S, Gebauer D. Clinical guideline for the management of odontogenic infections in the tertiary setting. Aust Dent J. 2017; 62(4): 46470. DOI: $10.1111 /$ adj. 12538

9. Holtmann H, Lommen J, Sander K, Kubler NR, Langie R. Odontogenic cervical necrotizing fasciitis and descending necrotizing mediastinitis in a diabetic patient: Literature review and report of a rare and fatal case. World J Oral Maxillofac Surg. 2018; 1(1): 1-4.

10. Hargreaves KM, Cohen S. Cohen pathway's of the Pulp, $10^{\text {th }}$ ed. St. Louis: Mosby-Elsevier; 2011. p. 785-820.

11. Hupp JR, Ferneini EM. Head, Neck, and Orofacial Infections: An Interdisciplinary Approach. $1^{\text {st }}$ ed. St. Louis: Mosby-Elsevier 2016. p. 203-20.

12. Bali R, Sharma P, Ghanghas P, Gupta N, Tiwari JD, Singh A. To Compare the Efficacy of C-Reactive Protein and Total Leucocyte Count as Markers for Monitoring the Course of Odontogenic, J Maxillofac Oral Surg. 2017
Sept;16(2):322-7. DOI: 10.1007/s12663-0160978-3

13. Miloro M, Ghali GE, Larsen PE, Peter D. Peterson's Principles of Oral and Maxillofacial Surgery - $3^{\text {rd }}$ ed. Connecticut. 2011. p. 841-55.

14. Sainuddin S, Hague R, Howson K, Clark S. New admission scoring criteria for patients with odontogenic infections: A pilot study. Br J Oral Maxilloc Surg. 2017;55:86-9. DOI: 10.1016/j. bjoms.2016.05.003

15. Sharma A, Giraddi G, Krishnan G, Shahi AK. Efficacy of serum prealbumin and crp levels as monitoring tools for patients with fascial space infections of odontogenic origin: a clinicobiochemical study, J Maxillofac Oral Surg 2014 Mar;13(1):1-9. DOI: 10.1007/ s12663-012-0376-4.

16. Cowin SC, Cardoso L. Blood and interstitial flow in the hierarchial pore space architecture of bone tissue. J Biomech. 2015 March;48(5):842-54. DOI: 10.1016/j. jbiomech.2014.12.013

17. Aloitibi N, Cloutier L, Khaldoun E, Bois E, Chirat M, Salvan D. Criteria for admission of odontogenic infections at high risk of deep neck space Infection. Eur Ann Otorhinolaryngology, Head Neck Dis. 2015;132:261-64. DOI: 10.1016/j.anorl.2015.08.007

18. Mirochnik R, Araidy S, Yaffe V, Abu El. Severity Score as Prognostic Factors for Management of infection of odontegenic origin, a study of 100 cases. Open J Stomatology. 2017;7:25-34. DOI: $10.4236 /$ ojst.2017.71002

19. Ziętarska M, Lipiec JK, Kraj L, Zaucha R, Małgorzewicz $S$. Nutritional status assessment in colorectal cancer patients qualified to systemic treatment. Contemp Oncol (Pozn). 2017;21(2):157-161. DOI: 10.5114/ wo.2017.68625.

20. Heim N, Wiedemeyer V, Reich RH, Martini M, The role of $\mathrm{C}$-reactive protein and white blood cell count in the prediction of length of stay in hospital and severity of odontogenic abscess. J Craniomaxillof Surg 2018;46(12):2220-26. DOI: $10.1016 / \mathrm{j} . j \mathrm{jcms} .2018 .10 .013$.

21. Simon AK, Hollander GA, MCMichael A. Evolution of the immune system in humans from infancy to old age. Proc Biol Sci. 2015 Dec 22;282(1821):20143085. DOI: 10.1098/ rspb.2014.3085. 
22. Saito CT, Gulinelli JL, Marão HF, Garcia Jr IR, Filho OM, Sonoda CK, et al. Occurrence of odontogenic infections in patients treated in a post graduation program on maxillofacial surgery and traumatology. J Craniofac Surg. 2011;22(5):1689-94. DOI: 10.1097/ SCS.0b013e31822e5c8d

23. Rasteniene $R$, Puriene $A$, Aleksejuniene J, Peciuliene V, Zaleckas L. Odontogenic Maxillofacial Infections: A Ten-Year Retrospective Analysis. Surg Infect (Larchmt) 2015:16(3):305-12. DOI: 10.1089/ sur.2013.264.

24. Sproston NR, Ashworth JJ. Role of C-Reactive Protein at Sites of Inflammation and Infection. Front. Immunol. 2018;9:754. DOI: 10.3389/ fimmu.2018.00754

25. Opitz D, Camerer C, Camerer DM, Raguse JD, Menneking $\mathrm{H}$, Hoffmeister $\mathrm{B}$, et al. Incidence and management of severe odontogenic infections-a retrospective analysis from 2004 to 2011. J Craniomaxillofac Surg 2015;43(2):2859. DOI: $10.1016 / j . j \mathrm{cms} .2014 .12 .002$

26. Bagul R, Chandan S, Dilip Sane V, Patil $S$, Yadav D. Comparative Evaluation of
C-Reactive Protein and WBC Count in Fascial Space Infections of Odontogenic Origin. J Maxillofac Oral Surg. 2017 Jun;16(2):238-42. DOI: $10.1007 / \mathrm{s} 12663-016-0953-\mathrm{z}$.

27. Savitri R, Karasutisna, Nurwiadh A. Description of odontogenic infection cases at the oral surgery polyclinic of Hasan Sadikin hospital Bandung, Indonesia. Padjadjaran J Dent 2012;24(1):47-52. DOI: 10.24198/pjd. vol24no1.15382.

28. Bali RK, Sharma P, Gaba S, Kaur A, Ghanghas P. A review of complications of odontogenic infections. Natl J Maxillofac Surg 2015;6:13643. DOI: $10.4103 / 0975-5950.183867$.

29. Michael JA, Hibbert SA. Presentation and management of facial swellings of odontogenic origin in children. Eur Arch Paediatr Dent 2014;15(4):259-68. DOI: 10.1007/s40368-0140110-7

30. Han Xiaodong, AnJingang, Zhang Yi, Gong Xi, and He Yang, Risk Factors for Life-Threatening Complications of Maxillofacial Space Infection. J Craniofac Surg 2016 Mar;27(2):385-90. DOI: $\underline{10.1097 / \text { SCS. } 0000000000002416 .}$ 